\title{
RESISTÊNCIA MECÂNICA DO SOLO À PENETRAÇÃO NA FILEIRA E ENTREFILEIRA DE CANA- DE-AÇÚCAR EM FUNÇÃO DA MECANIZAÇÃO
}

Fabio Alexandre Cavichioli ${ }^{1}$, Carlos Eduardo Angeli Furlani ${ }^{2}$, Anderson de Toledo ${ }^{3}$, Rouverson Pereira da Silva $^{4}$, Carlos Augusto Ribeiro ${ }^{5}$

\section{RESUMO}

A compactação dos solos agrícolas tem sido foco de estudos de diversos pesquisadores, nas mais variadas culturas em todas as regiões do País. Métodos de avaliação são comparados, em diferentes tipos de solo, e valores críticos são preconizados para determinadas culturas. Nesta pesquisa, foi avaliada a resistência do solo à penetração em área de produção mecanizada de cana-de-açúcar, com o objetivo de identificar os níveis de compactação, com a utilização de mapas de atributos, na fileira e na entrefileira de plantio. A avaliação da resistência mecânica do solo á penetração foi realizada após a colheita mecanizada (terceiro corte), utilizando um penetrógrafo eletrônico e receptor GPS acoplados a um quadriciclo. Com esta pesquisa inicial, pode-se concluir que o tráfego de máquinas na entrefileira de cana-deaçúcar causou alterações no perfil do solo, afetando os valores médios de RMSP até $50 \mathrm{~cm}$ de profundidade.

Palavras-chaves: compactação, GPS, penetrógrafo

\section{ABSTRACT \\ INTER AND INTRA-ROW SOIL MECHANICAL RESISTANCE TO PENETRATION IN SUGARCANE PLANTATION DUE TO MECHANIZATION}

Compaction of agricultural soils has been the focus of study by various researchers, in several crops in all regions of Brazil. Evaluation methods are compared with each other in different soil types, and critical values are recommended for certain crops. This study was done to determine inter- and intra- row soil compaction levels in an area of mechanized sugarcane production, with the use of attribute maps and the soil mechanical resistance to penetration (SMRP). The SMRP was evaluated after harvest, using the electronic penetrometer (PNT Titan of DLG Automação Industrial Ltda). This initial research showed that the agricultural machinery traffic between rows caused changes in the soil profile, affecting the average SMRP until $50 \mathrm{~cm}$.

Keywords: compaction, GPS, penetrographer

Recebido para publicação em 27/05/2010. Aprovado em 21/11/2011.

1- Engenheiro Agrônomo, Doutorando em Agronomia (Produção Vegetal), FCAV UNESP Jaboticabal-SP, cavichioli2003@hotmail.com. 2-Engenheiro Agrônomo, Prof. Dr., Depto de Engenharia Rural, FCAV UNESP Jaboticabal-SP.

3- Engenheiro Agrícola, Doutorando em Agronomia (Produção Vegetal), FCAV UNESP Jaboticabal.

4- Engenheiro Agrícola, Prof. Dr., Depto de Engenharia Rural, FCAV UNESP Jaboticabal-SP.

5- Engenheiro Eletricista, MSC. Agronomia (Ciência do Solo), DLG Automação.

46 REVENG

46-51 p. ENGENHARIA NA AGRICULTURA, VIÇOSA - MG, V.20 N.1, JANEIRO / FEVEREIRO 2012 


\section{INTRODUÇÃO}

A implantação de novas tecnologias visando aumento da produtividade e menor tempo de realização das operações agrícolas, normalmente induz a uma intensa mecanização dos sistemas de produção, que podem, em muitos casos, acarretar em degradação do solo, principalmente em longo prazo, independente do uso de métodos de conservação do solo.

$\mathrm{Na}$ agricultura tradicional, as áreas produtivas são tomadas como homogêneas em suas características, levando ao conceito da necessidade média da aplicação dos insumos e realização de operações para toda a área. Isto faz com que, no caso específico da compactação do solo, toda a área seja descompactada na mesma profundidade, quando essa necessidade poderia ser em menor profundidade e somente em áreas específicas.

O contínuo uso do solo, principalmente em áreas agrícolas totalmente mecanizadas, provoca aumento da heterogeneidade das características químicas e físicas do solo (SOUZA et al., 1999). Um dos atributos físicos mais adotados como indicativo da compactação do solo é a resistência mecânica do solo à penetração (RMSP), por apresentar relação direta com o crescimento das plantas e por ser mais eficiente na identificação de estados de compactação comparada à densidade do solo (FREDDI et al., 2006).

A variabilidade dentro do perfil do solo argiloso foi estudada por IAIA et al. (2006) na cultura de cana-de-açúcar e observaram redução gradativa da RMSP com o aumento da profundidade. Os maiores níveis de RMSP foram verificados até $25 \mathrm{~cm}$, e a partir desta até $50 \mathrm{~cm}$ decresceram, evidenciando duas camadas distintas. Somente a partir de $45 \mathrm{~cm}$ a RMSP foi inferior ao nível considerado, pelos autores, crítico para o crescimento das raízes (2 MPa). Segundo Beutler et al. (2006), valores de 2,0 a 3,0 MPa são limitantes à produtividade de soja.

A resistência do solo à penetração apresenta relação direta com a densidade do solo, sendo que sua determinação deve ser realizada no conteúdo de água retida na capacidade de campo (BENGOUGH et al., 2001). Contudo, no campo, isso nem sempre é possível, dessa forma, realiza-se a determinação da umidade no perfil do solo associada à RMSP.
ARMSP próxima de $2 \mathrm{MPa}$, quando determinada na umidade a capacidade de campo, promove restrição do crescimento das raízes em culturas semeadas no sistema de preparo convencional (ARSHAD et al., 1996), entretanto, em solos não revolvidos anualmente, são toleráveis valores de até $4 \mathrm{MPa}$ (ROQUE et al., 2003).

A resistência mecânica do solo à penetração na cultura da cana-de-açúcar é influenciada pelo número de cortes, devido ao acréscimo de operações mecanizadas realizadas na mesma área a cada safra. Diante deste raciocínio, realizou-se nesta pesquisa a avaliação da compactação do solo em área de produção mecanizada de cana-de-açúcar, com o objetivo de identificar, com a utilização de mapas de atributos para a resistência mecânica do solo à penetração, na fileira e na entrefileira de plantio.

\section{MATERIAL E MÉTODOS}

Este trabalho foi realizado em área de produção mecanizada de cana-de-açúcar, pertencente à Fazenda Santa Izabel, Jaboticabal - SP, coordenadas $21^{\circ} 18^{\prime} \mathrm{S}$ e $48^{\circ} 10^{\prime} \mathrm{W}$ e altitude média de $615 \mathrm{~m}$. A variedade de cana-de-açúcar foi a SP 90-1638, em terceiro corte num talhão de $9,15 \mathrm{ha}^{-1}$. O solo da área experimental é classificado como LATOSSOLO Vermelho eutroférrico (EMBRAPA, 1999). O clima da região é tropical com chuvas de verão (Aw) pela classificação de Köppen-Geiger, com temperatura média do mês mais frio superior a $18^{\circ} \mathrm{C}$, estação invernosa ausente e verão chuvoso.

As operações agrícolas realizadas foram: colheita mecanizada com colhedora marca Case $\mathrm{IH}$, modelo A 7700, em conjunto com tratores marca Case IH, modelo MXM 150, tracionando transbordos marca Case IH, modelo VTX 10000, operações de cultivo com trator marca Massey Ferguson, modelo MF 630 trabalhando com cultivador de discos e operações de aplicação de vinhaça e herbicida.

A avaliação da resistência mecânica do solo à penetração (RMSP) foi realizada em 34 pontos na fileira e 34 pontos na entrefileira de plantio da canade-açúcar, após a colheita mecanizada, utilizando um quadriciclo equipado com um penetrógrafo eletrônico e receptor GPS, desenvolvido em parceria do Laboratório de Máquinas e Mecanização 
Agrícola (LAMMA UNESP/Jaboticabal) e a empresa DLG automação, com apoio financeiro do $\mathrm{CNPq}$ (Figura 1). Este equipamento está em conformidade com a norma ASAE S313.3 (ASAE, 1996) e adquire dados até a profundidade de $55 \mathrm{~cm}$, a velocidade de penetração da haste é de $3 \mathrm{~cm} \mathrm{~s}^{-1}$ e freqüência de aquisição de $3 \mathrm{~Hz}$. Possui célula de carga com capacidade de $1500 \mathrm{~N}$, para medição da força normal de penetração da haste, motor elétrico $12 \mathrm{Vcc}$, para acionamento da haste e sensor indutivo-capacitivo para medição da profundidade de penetração, adquirindo um dado de força a cada centímetro de profundidade (neste trabalho utilizaram-se camadas de $10 \mathrm{em} 10 \mathrm{~cm}$ ).

O penetrógrafo possui o software PNT-View (desenvolvido pela DLG Automação Industrial Ltda) para aquisição e análise de dados. Esses dados foram armazenados na memória do aparelho e foram exportados para o software PNT-View, que é responsável pela aquisição dos dados obtidos no campo, inclusive para a geração dos mapas que permitem a visualização dos valores de RMSP.

Para a criação dos mapas o software baseiase nas coordenadas gravadas de cada ponto amostrado, fazendo a interpolação dos dados de RMSP, pelo método do inverso do quadrado da distância, para estimar os valores das áreas não amostradas. A interpolação é calculada por um algoritmo que utiliza a média ponderada do valor de RMSP pela distância dos n vizinhos de cada ponto, sendo o valor de $\mathrm{n}$ determinado na configuração do software, que no caso foi configurado para 4 vizinhos.

Por meio dos mapas interpolados é possível visualizar a distribuição espacial dos valores de RMSP medidos, permitindo fazer comparações visuais dos níveis de compactação de cada tratamento e de cada profundidade do perfil do solo amostrado. No experimento utilizou-se haste de ponteira cônica com área de $71 \mathrm{~mm}^{2}$.

Amostras de solo foram coletadas com auxílio de um trado manual e cápsulas de alumínio, até a profundidade de $50 \mathrm{~cm}$, em intervalos de $10 \mathrm{~cm}$, durante as avaliações de RMSP, foram utilizadas para obtenção do teor médio de água no solo pelo método gravimétrico padrão, descrito em Embrapa (1979). Foram escolhidos 10 pontos aleatórios dentro da área experimental para a caracterização do teor de água do solo no momento das avaliações.

A estatística descritiva foi utilizada para analisar os principais parâmetros estatísticos dos valores de RMSP encontrados. Em seguida foi feito análise de variância e quando o teste $\mathrm{F}$ foi significativo, aplicou-se o teste de comparação de médias de Tukey, à $5 \%$ de probabilidade, para as variáveis RMSP e teor de água no solo.
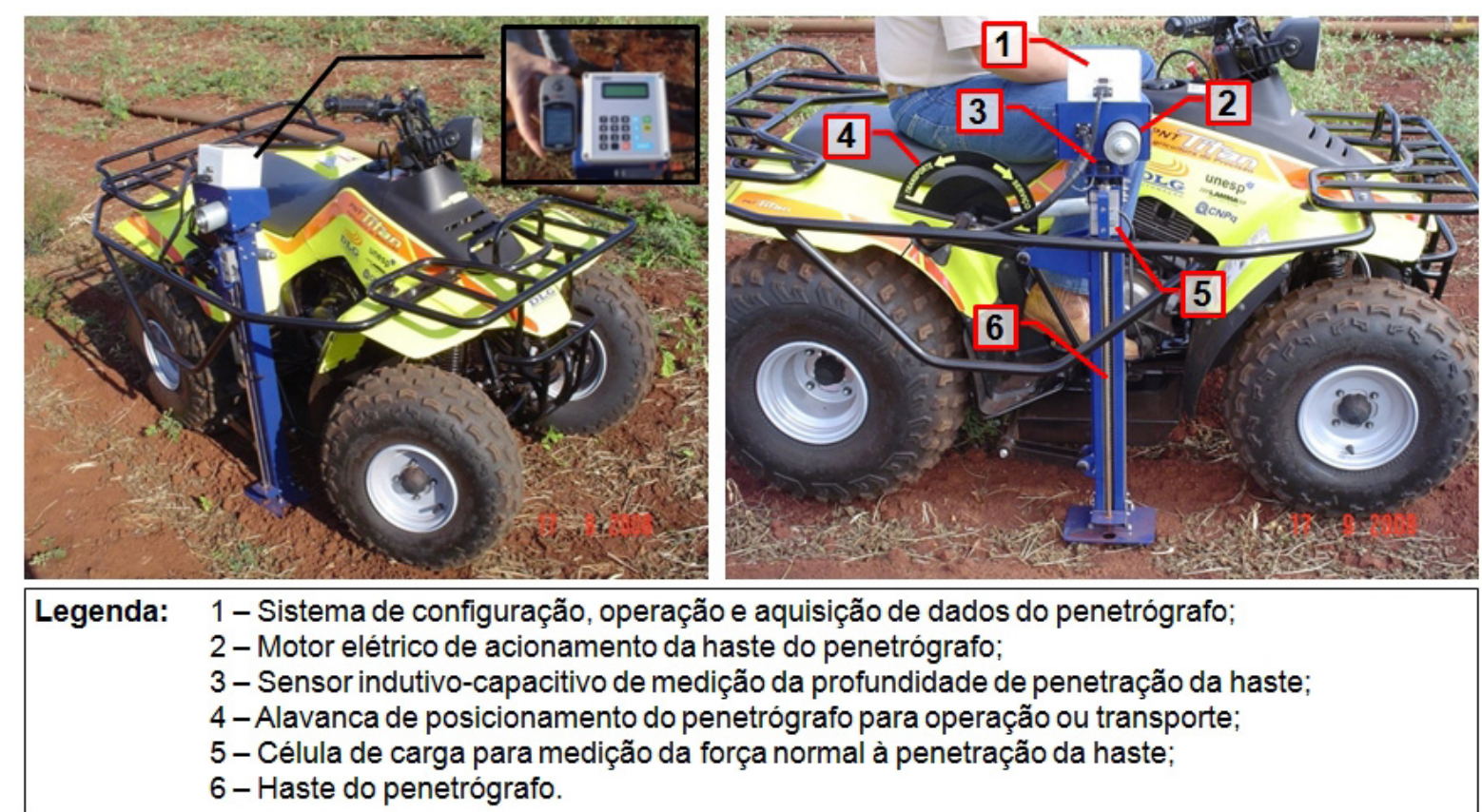

Figura 1. Quadriciclo equipado com penetrógrafo eletrônico e receptor GPS 


\section{RESULTADOS E DISCUSSÃO}

Os valores de RMSP média e máxima, coeficiente de variação e o teor de água do solo na avaliação são apresentados no Quadro 1. Para a RMSP média é evidente o aumento da compactação com a profundidade na fileira e na entrefileira de plantio de cana-de-açúcar. Somente entre as profundidades de $11-20 \mathrm{~cm}$ e $21-30 \mathrm{~cm}$ da entrefileira não houve diferença estatística na RMSP média, devido aos tratos culturais que são realizados na entrelinha da cultura como exemplo as operações de manejo da cultura como o cultivo que se utiliza equipamentos com hastes sendo que esta hastes atuam na entrelinha da cultura. Na comparação entre as profundidades na fileira e entrefileira, somente para a última camada não houve diferença, sendo a RMSP sempre maior para a entrefileira, devido ao tráfego de máquinas agrícolas. Os valores máximos encontrados de RMSP na fileira são bem maiores que os valores médios devido as camadas compactadas no solo, sendo que a maioria das operações de tratos culturais são realizadas nas entrelinhas da cultura.

NasFiguras 2e 3 são visualizados respectivamente os mapas de RMSP média e máxima, para fileira (A) e entrefileira (B).

A compactação média encontrada nas fileiras de plantio (FIGURA 2A) foi menor do que na entrefileira (FIGURA 2B), com maior parte da área com valores entre 2 e $4 \mathrm{MPa}$, enquanto na entrefileira estes valores se concentraram entre 4 e $6 \mathrm{MPa}$. Esta diferença na média da RMSP é justificada pela concentração do tráfego das máquinas durante as safras da cultura. Para os mapas de RMSP

Quadro 1. Valores de resistência mecânica do solo à penetração (RMSP) e teor de água do solo para as profundidades avaliadas na fileira (FIL) e entrefileira (EF) de plantio da cana-de-açúcar

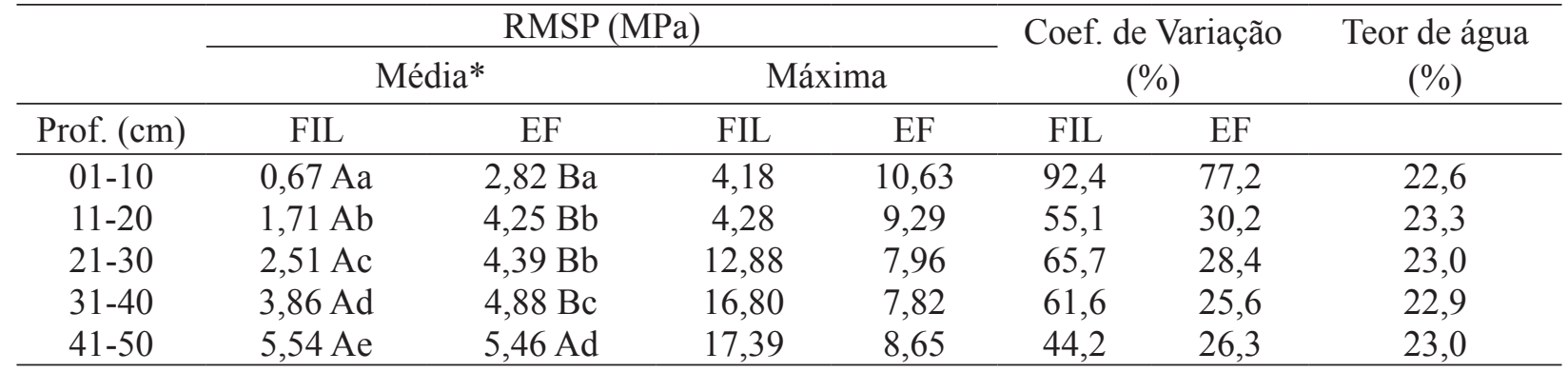

*Médias seguidas de mesma letra maiúscula nas linhas e minúscula nas colunas não diferem pelo teste de Tukey a 5\% de probabilidade

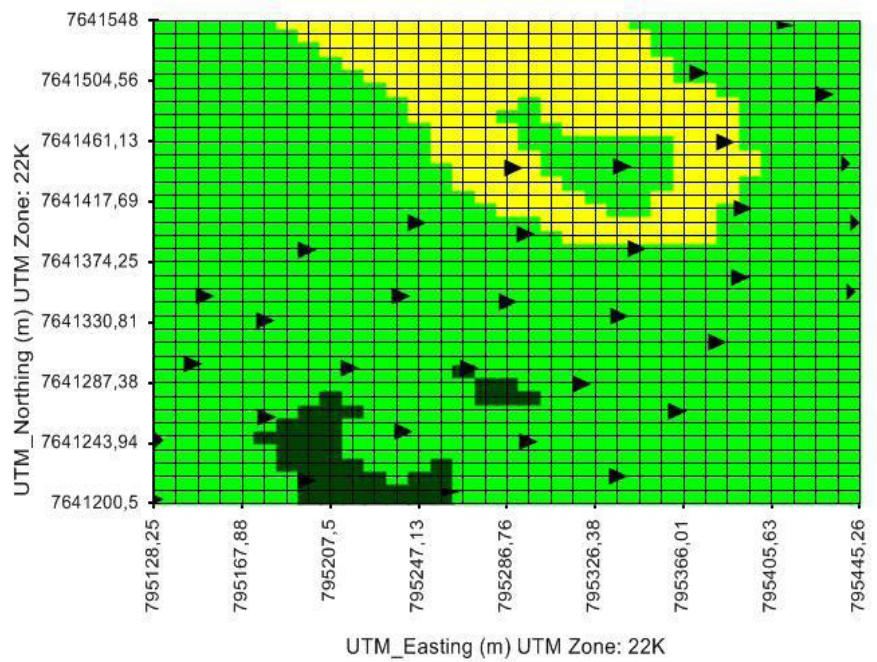

(A)

Legenda: $\square 0-2 \mathrm{MPa} \quad \square 2-4 \mathrm{MPa} \quad \square 4-6 \mathrm{MPa}$

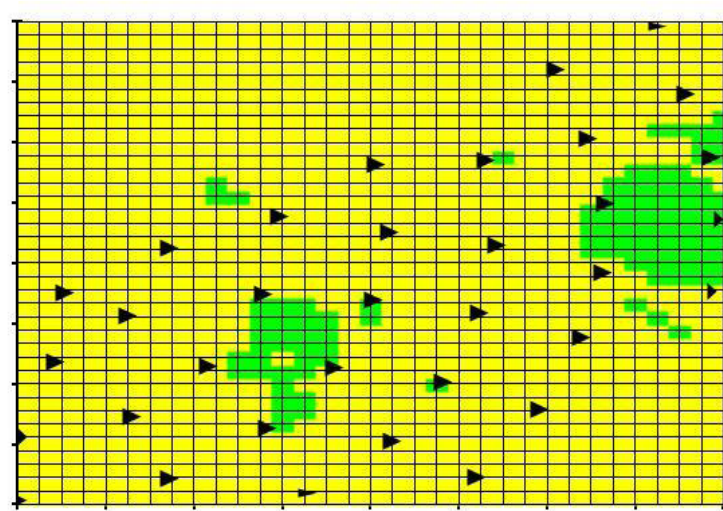

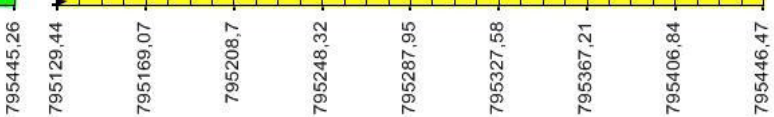

UTM_Easting (m) UTM Zone: $22 \mathrm{~K}$

(B)

- $10 \mathrm{MPa}$

$10-12 \mathrm{MPa}$

Figura 2. RMSP média na fileira (A) e entrefileira (B) de plantio até $50 \mathrm{~cm}$ de profundidade. 


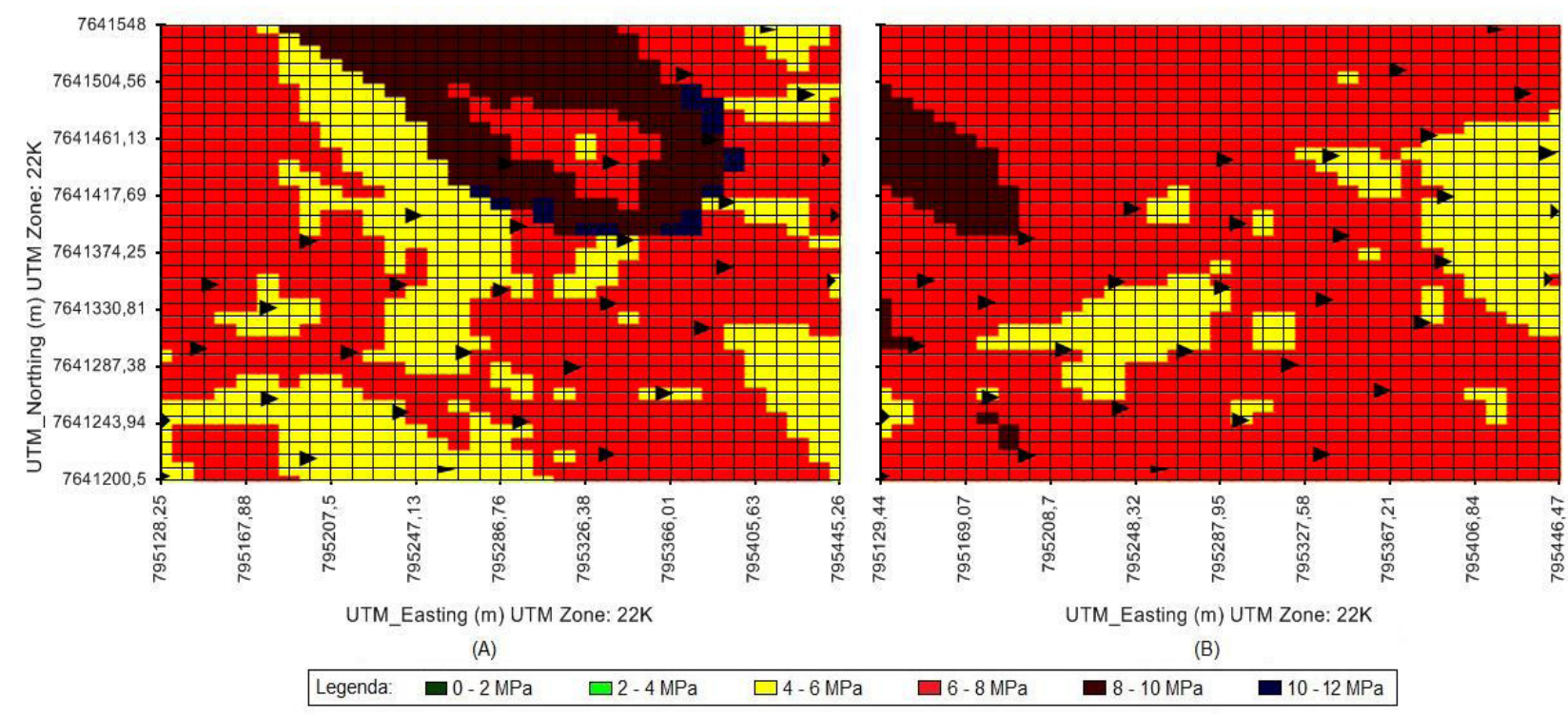

Figura 3. RMSP máxima na fileira (A) e entrefileira (B) de plantio até $50 \mathrm{~cm}$ de profundidade.

máxima, grande parte dos valores encontrase abaixo de $25 \mathrm{~cm}$ de profundidade e com valores elevados, acima de $4 \mathrm{MPa}$, porque há um grande índice de tráfego de máquinas durante os tratos culturais até a colheita, sendo que essa área é uma área se terceiro corte. $\mathrm{Na}$ entrefileira, os valores máximos de RMSP foram maiores somente nas duas primeiras camadas, indicando que na fileira de plantio, após $20 \mathrm{~cm}$ de profundidade, os níveis de compactação são elevados, podendo ser em função da distribuição de forças no solo, ou ainda pela descompactação gerada pelas próprias raízes nas camadas superficiais.

\section{CONCLUSÕES}

- O tráfego de máquinas na entrefileira de canade-açúcar causou alterações no perfil do solo, afetando os valores médios de RMSP até $50 \mathrm{~cm}$ de profundidade;

- A média da RMSP foi superior na entrefileira de plantio de cana-de-açúcar até $40 \mathrm{~cm}$ de profundidade, não havendo diferença para a camada de 41-50 cm; e

- Altos valores de RMSP foram encontrados para as duas situações avaliadas, principalmente nas camadas de solo mais profundas.

\section{REFERÊNCIAS BIBLIOGRÁFICAS}

AMERICAN SOCIETY OF AGRICULTURAL ENGINEERS. Soil cone penetrometer. In: ASAE standards 1996: standards engineering practices data. St. Joseph, 1996. p.719. (ASAE S 313.3).

ARSHAD, M.A.; LOWERY, B.; GROSSMAN, B. Physical tests for monitoring soil quality. In: DORAN, J.W.; JONES, A.J. (ed.). Methods for assessing soil quality. Madison: Soil Science Society of America, 1996. p.123-141 (SSSA Special publication 49)

BENGOUGH, A.G.; CAMPBELL, D.J. \& O'SULLIVAN, M.F. Penetrometer techniques in relation to soil compaction and root growth. In: SMITH, K.A. \& MULLINS, C.E, eds. Soil environmental analysis: physical methods. 2.ed. Marcel Decher, 2001. p.377-403.

BEUTLER, A.N.; CENTURION, J.F.; SILVA, A.P.; BARBOSA, J.C. Intervalo hídrico ótimo e produtividade de cultivares de soja. Revista Brasileira de Engenharia Agrícola e Ambiental, Campina Grande, v.10, n.3, p.639-645, jul./set. 2006.

EMPRESA BRASILEIRA DE PESQUISA AGROPECUÁRIA. Serviço Nacional de 
levantamento e conservação do solo. Manual de métodos e análise de solo. Edição única. Rio de Janeiro: Editado pela EMBRAPA, 1979. não paginado.

\section{EMPRESA BRASILEIRA DE PESQUISA} AGROPECUÁRIA. Serviço Nacional de Levantamento e Conservação dos Solos. Sistema brasileiro de classificação de solos. Brasília: Embrapa Produção de Informação, 1999. 412 p.

FREDDI, O.S.; CARVALHO, M. P.; VERONESI JÚNIOR, V.; CARVALHO, G. J. Produtividade do milho relacionada com a resistência mecânica à penetração do solo sob preparo convencional. Engenharia Agrícola, Jaboticabal, v. 26, n. 1, p. 113-121, jan./abr. 2006.

IAIA, A.M.; MAIA, J.C.S.; KIM, M.E. Uso do penetrômetro eletrônico na avaliação da resistência mecânica do solo cultivado com cana-de-açúcar.
Revista Brasileira de Engenharia Agrícola e Ambiental. Campina Grande-PB, v.10, n.2, p.523530, abr./jun, 2006.

ROQUE, C.G., CENTURION, J.F., ALENCAR, G.V., BEUTLER, A.N., PEREIRA, G.T., ANDRIOLI, I. Comparação de dois penetrômetros na avaliação da resistência à penetração de um Latossolo Vermelho sob diferentes usos. Acta Scientiarum: Agronomy, Maringá, v.25, n.1, p. 53-57, jan./mar. 2003.

SOUZA, E.G.; JOHANN, J.A.; ROCHA, J.V.; RIBEIRO, S.R.A.; SILVA, M.S.; URIBEOPAZO, M.A.; MOLIN, J.P.; OLIVEIRA, E.F.; NÓBREGA, L.H.P. Variabilidade espacial dos atributos químicos do solo em um Latossolo Roxo Distrófico da região de Cascavel - PR. Engenharia Agrícola, Jaboticabal- SP, v.18, n.3, p.80-92, mar. 1999. 